\title{
Disentangling crashes from tail events
}

\author{
Sofiane Aboura* \\ Université de Paris-Dauphine, France
}

October 15, 2010

\begin{abstract}
The study of tail events has become a central preoccupation for academics, investors and policy makers, given the recent financial turmoil. However, what differentiates a crash from a tail event? This article answers this question by taking a risk management perspective that is based on an augmented extreme value theory methodology with an application to the French stock market (1968-2008). Our empirical results indicate that the French stock market experienced only two crashes in 2007-2008 among the 12 identified over the whole period.

Key Words: Extreme Value Theory, Volatility, Risk Management. JEL Classification: C4, G13, G32
\end{abstract}

\section{Introduction}

Financial markets throughout the world have been subject to financial disasters during the last twenty years (October 1987, the Long Term Capital

*The paper benefited from very helpful discussions with Paul Embrechts, Alexander McNeil, Raphael Franck, Xavier Gabaix, Bill Megginson, Abraham Lioui, Karine Michalon, Gilles Chemla, Daniel Zajdenweber, Yannick Viossat, Clotilde Napp, Aymeric Kalife and Michel Crouhy. I would like to thank all the participants of the International French Association of Finance (Saint-Malo, 2010) and the Multinational Finance Conference (Barcelona, 2010). All errors remain with the author. Correspondance: Sofiane Aboura, Department of Finance, DRM-Finance, Université de Paris-Dauphine, Place du Maréchal de Lattre de Tassigny, 75775 Paris cedex 16, France. Phone : $+33+1+44054565$, Email: Sofiane.Aboura@dauphine.fr. 
Management collapse and Russian debt crisis, the Latin American and Asian currency crises and more recently, the U.S. mortgage credit market turmoil, followed by the bankruptcy of Lehman Brothers and the world's biggest-ever trading loss at Société Générale). Stock market crashes are some of the most fascinating subjects in finance. However, there is no unique definition of a crash. Financial literature on that topic creates some confusion on rare events usually called extremes, crashes or crises. Even if it not straightforward to define a priori a crash, the investors may be able to identify a posteriori a crash through its panic effect; it can have been induced by systemic risk, liquidity risk, regulatory risk or even trading algorithm risk. For example, the biggest intraday drop in the history of the Dow Jones index on May 6, 2010 was interpreted by market participants as a crash. Indeed, the computerautomated trades cause a total drop of $9.16 \%$ from the previous day's close; however, the market rebounded to close down by 348 points.

The Extreme Value Theory (EVT) has widely documented ${ }^{1}$ ways in which extreme events can be quantified. A general discussion on the application of EVT to finance is proposed by Embrechts, Klüppelberg and Mikosch (1997), McNeil (1999), Coles (2001), and Beirlant, Goegebeur, Segers and Teugels (2004). However, Longin (1993) remains the only one in this literature to address explicitly the question of the existence of crashes. Longin (2001) addresses the same question by applying EVT to two sub-samples; one subsample of the so-called crashes and an other sub-sample from other minima. He finally concludes that crashes and non-crashes have no statistical differences because they are drawn from the same unconditional distribution of extremes. This conclusion may have closed the debate, earlier than expected, in this literature. Indeed, if the conclusion is not questionable within this literature ${ }^{2}$, the application of EVT to raw returns may cause a problem to identify real crashes from large negative returns. Actually, the investors

\footnotetext{
${ }^{1}$ Longin (1993), Longin (1996), McNeil (1997), Danielsson and de Vries (1997), McNeil and Saladin (1998), Christoffersen, Diebold and Schuermann (1998), Diebold, Shuermann and Stroughair (1999), McNeil and Frey (2000), Jondeau and Rockinger (2003), Gilli and Këllezi (2000), Bali and Neftci (2002), LeBaron and Samanta (2004), Danielsson and Morimoto (2000), Longin (2001), Gençay, Selçuk and Ulugülyagci (2003), Mandira (2004), Tolikas and Brown (2005), Gettingby, Sinclair, Power and Brown (2006). This literature has become risk management oriented.

${ }^{2}$ This issue has been a debate among economists (see Gabaix, Gopikrishnan, Plerou, Stanley (2005) who conclude that daily crashes are not outliers to the distribution of returns).
} 
are not symmetrically affected by a negative return that comes from a high volatility period or by an equal negative return that comes from a low volatility period. Indeed, investors are more cautious during high volatility period and may panic much more if an extreme event occurs during a low volatility period due to the surprise effect. For this reason, this article considers the role of volatility in the crash definition.

The first question to address is why is it useful to identify a crash? Because this may helps investors, regulators and policymakers to differentiate warning signals according to their scale level; for these same reasons, the NBER defines expansion cycles and recession cycles in the US since 1854. For instance, the recognition of crash events may justify intervention policies from economic agents with the right timing. For example, would the identification of a crash in 2007 after the collapse of the U.S. Housing Bubble have forced the policymakers to save Lehman Brothers and avoid the huge international volatility spill over of 2008? However, all crashes do not lead to a macro-economic downturn; for example, the 1987 stock market crash did not generate an economic contraction. Therefore, if all crashes affect the risk aversion of investors, they do not equally affect the economic business cycles. The second question is how can we define a crash versus a tail event? Defining a tail event is straightforward. Indeed, it corresponds to any return located in the tails of the distribution; an adverse tail event represents an negative extreme return for a long position and a positive extreme return for a short position. In addition, if a crash (anti-crash) corresponds to a negative (positive) extreme return, the reverse is not true. Indeed, the largest negative return during a bullish period will surely not be a crash; for example, the minimal return of the S\&P 500 stock index during year 1999 is $-2.85 \%$.

We introduce a definition of stock market crash that is risk-management oriented; per hypothesis, stock market crash is defined as being sudden, significant and brief:

Sudden event. This corresponds to a price variation that is independent of the current volatility regime. It refers to a high-return shock during a period of low volatility and not to a small-return shock during a period of high volatility. Given the asymmetric nature of volatility, returns and volatility are negatively related in equity markets; this relation is more pronounced 
for large negative returns. When the volatility is high, financial markets overreact to bad news (See e.g. Black (1976), Campbell and Hentschel (1992), Beckaert and $\mathrm{Wu}$ (1992) for the so-called "leverage effect" and "feedback effect" hypotheses); this over-reaction is characterized by large volumes of sell orders during stress periods, which contribute to exacerbate downside volatility (see more recently Gabaix, Gopikrishnan, Plerou and Stanley (2003) on the relationship between large fluctuations in prices, trading volume and the number of trades.). In contrast, when the volatility is low, bad news can drive markets into unexpected collapse; this was the case after the heart attack of the U.S. President Eisenhower on September, 261955 with a one-day drop of $6.85 \%$ on the S\&P 500 stock index.

Significant decline. This corresponds to a price variation whose magnitude is high (domestic crash) and induces systemic risk throughout the world financial markets, increasing the stock market index correlation levels (international crash). Equity markets react not only to their domestic political and economic factors but also to trading pressures around the world. Such was the case on October 19, 1987 with a decline of $22.89 \%$; this one-day drop is comparable to the percentage drop that occurred over October 28 and 29, 1929 with a respective decline of $12.82 \%$ and $11.73 \%$.

One-day horizon. Shiller (1988) notices that "The concentration of attention on 1987 as a unique year in stock market history is to some extent an artifact of the one-day interval chosen." But if the shock is sudden and significant, it is almost impossible to hedge a portfolio within a one-day horizon. In that sense, the one-day interval choice is no longer artificial. Choosing a longer period for identifying a crash remains possible from a macro-economic perspective, but it will be no longer relevant for a risk management perspective because the crash is supposed to be sudden. Choosing a shorter period for identifying a crash is limited to the existence of circuit-breakers; for example, trigger levels for a market-wide trading halt are set at 10\%, 20\% and $30 \%$ of the Dow Jones index; another example in France, when the price movement of a share exceeds $10 \%$ from the quoted price at the close of the previous market day, quotation is suspended for 15 minutes. These trading curbs limit physically the possibility of intra-day crashes. In addition, trading pressures may induce several intra-day trading halts whose global effect will appear in the daily closing price. Therefore, we argue that it is almost 
impossible to hedge a portfolio against a crash within a time period of one day or less.

The purpose of this article is therefore to disentangle crashes from tail events. An augmented extreme value theory methodology is employed. In addition, an application to the French stock market index is provided, using the longest daily time series ever used (1968-2008) for this country. This choice is motivated by a long history of crashes illustrated by recent literature $^{3}$.

The remainder of this article is organized as follows. Section 2 synthesizes the theoretical background of extreme value theory used in the empirical section. Section 3 presents an analysis of the data, the filtering process and its economic implications. Section 4 analyses the tail distributions to differentiate crashes from extremes. Section 5 gives the conclusions.

\section{Methodology}

\subsection{Tail distribution}

Let $X_{1}, \ldots X_{n}$ be a sequence of random variables corresponding to stock returns. If these variables are independent and identically distributed (i.i.d.) and if $F$ is the cumulative distribution function then,

$$
\operatorname{Pr}\left(M_{n}<x\right)=\operatorname{Pr}\left(\max \left(X_{1}<x, \ldots, X_{n}<x\right)=(F(x))^{n}\right.
$$

\footnotetext{
${ }^{3}$ Many authors (e.g., Gallais-Hamonno and Arbulu (2002), Le Bris (2008), Le Bris and Hautcoeur (2008)) provide a rich long-term analysis of the French market's extreme behavior. Since there are no official statistics on any aggregate stock market index from the XIX century, they did an important work of recomposing a French stock market index a posteriori. In contrast, in this study, we rely on daily available prices. They use monthly returns (Gallais-Hamonno and Arbulu (2002) recognize that using monthly returns force them to remain under a Gaussian framework; they also recongnize that a high monthly variation can appear as an extreme event while it can stem from successive weak daily negative returns), while we use daily returns; they provide a historical perspective, while we also consider a forecasting outlook; they evaluate market performance, while we discuss the risk management implications; they usually define crashes as standard deviation multiples of monthly periods (Gallais-Hamonno and Arbulu (2002) define crashes as + / 3 standard deviations versus $+/-2.5$ for Le Bris (2008)), while we test a less restricted definition of crash, based on an extreme value theory approach.
} 
This has two consequences. First, the law of maxima can be easily obtained once we know $F$. Second, the law of minima is directly deduced from the law of maxima since we have $M_{n}=\max _{i=1, \ldots, n}\left(X_{i}\right)=-\min _{i=1, \ldots, n}\left(-x_{i}\right)$. Therefore, we only expose the part of the theory for the upper tail of the distribution. Let $F$ be an unknown function and look for approximate families of models $F^{n}$, which can be estimated from extreme observations only. We consider the behavior of $F^{n}$ as $n \longrightarrow \infty$. Let us consider a distribution function $F_{u}$ representing a probability that the value of $X$ exceeds the threshold $u$ by at most an amount $x$ given that $X$ exceeds the threshold $u$. The conditional distribution of excess losses over the threshold $u$ is defined as,

$$
F_{u}(x)=\operatorname{Pr}(X-u \leq x \mid X>u)
$$

The conditional probability can be written as

$$
F_{u}(x)=\frac{F(x+u)-F(u)}{1-F(u)}
$$

It may be difficult to compute $F_{u}$ as there are few observations in the considered area. However, Balkema and de Haan (1974) and Pickands (1975) showed that when the threshold $u$ is sufficiently high, the distribution function $F_{u}$ of the excess beyond this threshold can be approximated by the Generalized Pareto Distribution (GPD)

$$
F_{u}(x) \approx G_{\xi, \beta}(x)
$$

This limit distribution has a general form given by

$$
G_{\xi, \beta}(x)= \begin{cases}1-(1+\xi x / \beta)^{-1 / \xi}, & \text { for } \xi \neq 0 \\ 1-\exp (-x / \beta), & \text { for } \xi=0\end{cases}
$$

where $\beta \geq 0$ and where $x \geq 0$ when $\xi \geq 0$ and where $0 \leq x \leq-\beta / \xi$ when $\xi<0$. $\beta$ is a scaling parameter and $\xi$ is the tail index. The tail index is an indication of the tail heaviness, the larger $\xi$, the heavier the tail. This distribution encompasses other type of distributions. If $\xi>0$ $(\xi<0)$ then it is a reformulated version of the ordinary Pareto distribution (Pareto type II distribution) and if $\xi=0$, it corresponds to the exponential distribution. Smith (1987) showed that the maximum likelihood estimates of the GP distribution parameters are consistent and asymptotically normal for 
large samples provided that $\xi>-0.5$. In contrast to the normal distribution, which is defined for each moment, the GPD heavy-tailed distribution is not necessarily defined for each moment. Indeed, a large set of data in physics or insurance have infinite second moments. The tail index parameter helps examine how many finite moments the marginal distributions have. For example, an estimate of $\xi<0.5$ implies finite variance; an estimate of $\xi<$ 0.25 implies a finite fourth moment, etc.

\subsection{Threshold selection}

Threshold selection is subject to a trade off between finding a high threshold where the tail estimate has a low bias with a high variance or finding a low threshold where the tail estimate has a high bias with a low variance. The standard practice, to overcome the balance between bias and variance, requires adopting the lowest threshold as possible. There are two families of approaches for threshold selection. The first one is visual inspection and the second one is automatic selection. Visual selection denotes a plausible threshold choice based on the results of the two or more plot methods. Adaptive selection denotes the application of an automated method which aims at minimizing asymptotic mean squared error (see Beirlant et al. (2004), Section 4.7 ii).

We follow Gumbel (1958), Embrechts, Kluppelberg and Mikosch (1997) and Coles (2001) who suggest visual inspection methods for the observation of the tail region. Two approaches exist. The first approach corresponds to explanatory techniques carried out before the model estimation. The second approach corresponds to the assessment of the parameter estimate stability while fitting various models through a range of different thresholds. The first visual inspection method is based on the mean of excesses of the GPD defined as,

$$
E(X-u \mid X>u)=\frac{\sigma_{u}}{1-\xi}
$$

Denote $\sigma_{u}$ the value of the GPD scale parameter for a threshold $u>u_{0}$. The sample mean excess function is termed mean residual life plot (MRLP). The threshold detection is done by choosing the smallest observation to the right of which the mean excess function remains approximately linear as a function of the ordered data. Confidence intervals are associated to the graph 
given the approximate normality of sample means. Let $n_{u}$ be the number of exceedances over the threshold $u$, the MRLP is

$$
\left[u, \frac{1}{n_{u}} \sum_{i=1}^{u}\left(x_{i}-u\right)\right]
$$

However, MRLP can be difficult to interpret for threshold detection. A complementary visual method is to check for parameter stability. It corresponds to the second visual inspection method that involves fitting the GPD over a range of thresholds. This method allows observation of both the parameter estimate stability and variance. A range of possible thresholds would correspond to these criteria of relative stability and low variance. Indeed, plotting $\widehat{\xi}$ with its confidence intervals against $u$ allows the selection of a threshold that is as low as possible, such as selecting $u_{0}$ for which the estimates of $\xi$ remain near constant. It is defined by

$$
\left[\widehat{\xi}, G_{\xi, \beta}(x)=1-(1+\xi x / \beta)^{-1 / \xi}\right]
$$

For the optimal threshold selection method, let us consider an ordered sample of size $n_{u}, X_{n_{u}}, \ldots, X_{1}$ with $X_{k}$ being the $n_{u}^{\text {th }}$ upper order statistic. The Hill (1975) estimator is defined by

$$
\left[n_{u}, \widehat{\xi}_{n_{u}}^{H}=\frac{1}{n_{u}} \sum_{i=1}^{n_{u}}\left(\log X_{n-i+1}-\log X_{n-n_{u}}\right)\right]
$$

The Hill estimator is asymptotically normal. The choice of the Hill index is motivated by the fact that it has been proven to be efficient in the case of a Fréchet-type distribution (Longin (1996)). However, an important issue is to choose an appropriate $n_{u}$, which determines the red line between the tails and the centre of the distribution. The more $n_{u}$ increases, the more the bias is large but with small variance. The Hill' estimator is of practical use for determining the threshold by drawing a Hill-plot. The value of $n_{u}$ can be inferred by identifying a stable region in the graphic. However, the Hill plot does not quite stabilize throughout its range and therefore it is usually hard to come up with a value for $n_{u}$. It has been popular for the optimal threshold ${ }^{4}$ to be estimated such that the bias and variance of the estimated

\footnotetext{
${ }^{4}$ Many researchers have tried to overcome this problem of finding the optimal threshold. Among then, Hall and Welsh (1985), Hall (1990), Dacorogna, Muller, Pictet and de Vries (1994), Beirlant, Vynckier and Teugels (1996), Danielsson and de Vries (1997), Daniels-
} 
Hill tail index vanish at the same rate and where the mean squared error is asymptotically minimized. Usually, AMSE is obtained through a sub-sample bootstrap procedure.

\subsection{Tail risk management measures}

Every day risk management practices require evaluating the potential risk of loss. The recent severity of losses that struck the banking system requires extreme-oriented risk-measures. First, the Value-at-Risk (VaR) approach has become the benchmark risk measure for bank risk management. VaR summarizes the expected loss over a target horizon within a given confidence interval. It corresponds to a decline in the portfolio market value over a given horizon for a given probability level. A loss which exceeds the VaR threshold is termed a VaR break. Accurate estimation of the VaR is important but is subject to a traditional trade-off between risk and returns. Indeed, if the risk management overestimates the VaR, the trading desk return objectives may not be reached and the top management will impose a penalty on their personal wealth. In contrast, if the risk management undererestimates the VaR, the trading desk risk constraints may not be reached and the top management will impose a penalty on their personnel wealth. In any cases, VaR calculation often requires determining the probability distribution of the portfolio value change. However, there is no need to fully identify the probability distribution because only the extreme quantiles are of interest. Extreme VaR estimates are computed by inverting the tail estimation formula based on the loss distribution

$$
\operatorname{VaR}_{q}=F^{-1}(q)
$$

where the quantile function $F^{-1}$ is the inverse of $F$ and $q$ is the $q^{\text {th }}$ quantile of the distribution $F$ of profit and loss. We recall that $n$ is total sample size and $n_{u}$ the number of exceedances over the threshold $u$, so the tail estimator is given by

$$
F(x)=1-\frac{n_{u}}{n}\left(1+\xi \frac{x-u}{\beta}\right)^{-1 / \xi}
$$

son, de Haan, Peng and de Vries (2001), de Sousa and Michailidis (2004), and Beirlant, Goegebeur, Teugels and Segers (2004). The optimal tail size may vary from one method to another; however, the tail estimates remain generally stable. 
The VaR expression can be computed upon the maximum likelihood GPD parameter estimators

$$
V a R_{q}=u+\frac{\beta}{\xi}\left[\left(\frac{n_{u}}{n}(1-q)\right)^{-\xi}-1\right]
$$

VaR models have been criticized for their inadequacy. First, VaR can be misleading during volatile periods (e.g., Yamai and Yossiba (2005), Bao et al. (2006)); however, the use of GPD-VaR on GARCH-filtered data answers this problem. Second, VaR disregards any loss beyond the VaR level. Third, it has not the nice property of sub-additivity, in that the VaR of a portfolio can be higher than the sum of the respective VaRs of each individual asset in the portfolio (Artzner, et al. (1999)). For example, the failure of VaR to be sub-additive can drive the clearinghouse to be exposed to large adverse price movements. However, Danielsson, et al. (2005) demonstrate that VaR is subadditive for the tails of all fat-tailed distributions, provided that the tails are not super fat (e.g., an asset that has a first moment that is not defined). Second, a complementary measure known as the Expected Shortfall (ES) is usually used in, for example, margin requirements. This accounts for the sizes of tail losses since it evaluates the expected loss size given that VaR is exceeded

$$
E S_{q}=V a R_{q}+E\left(X-V a R_{q} \mid X>V a R_{q}\right)
$$

where the second term corresponds to the mean excess function over the threshold $V a R_{q}$. The explicit value for expected shortfall related to the VaR is given by

$$
E S_{q}=\frac{V a R_{q}}{1-\xi}+\frac{\beta-\xi u}{1-\xi}
$$

Filtered VaR and ES models are computed using the standardized return series. Indeed, most of the recent literature confirms the superior in and out-of-sample performance of the risk management models when combining a heavy-tailed GARCH filter with an extreme value theory-based approach (McNeil (1999), Acerbi (2002), Kuester, et al. (2005), Inui and Kijima (2005), Martins and Yao (2006), and Ozun, et al. (2007)). In fact, Kuester, et al. (2005) note precisely that the introduction of GARCH volatility dynamics almost uniformly improves VaR prediction performance in contrast with the unconditional approach. Third, the last measure known as the return level 
(Gumbel (1941)) is convenient for both model presentation and validation. The effect of extrapolation is highlighted. Scarcity produces large variance estimates. Let term $\zeta_{u}$ be the probability of exceeding the threshold $u$

$$
\operatorname{Pr}(X>u)=\zeta_{u}=\frac{n_{u}}{n}
$$

Consider $x_{m}$ as the return level that is exceeded on average once every $m$ observations. It is solution of

$$
\operatorname{Pr}(X>u)=\zeta_{u}\left[1+\xi\left(\frac{x_{m}-u}{\sigma}\right)\right]^{-1 / \xi}=\frac{1}{m}
$$

Equivalently, the $m-$ observation return level is

$$
x_{m}=u+\frac{\sigma}{\xi}\left[\left(m \zeta_{u}\right)^{\xi}-1\right]
$$

Return levels are expressed in annual scale so that the $N$-year return level is the level expected to be exceeded once every $N$ years. Consider $n_{250}$ as the average number of trading days per year with $m=N \times n_{250}$. The $N$-year return level then becomes

$$
x_{m}=u+\frac{\sigma}{\xi}\left[\left(N \times n_{250} \zeta_{u}\right)^{\xi}-1\right]
$$

\section{Data analysis}

\subsection{Data description}

The database ${ }^{5}$ consists of 10,017 daily stock prices that span the period of time from September, 30th 1968 to December 31, 2008. The French stock index known as the "Indice Général CAC" has been recomputed after the 1987 stock market crash and renamed as "CAC 40". The closing price was set to 1000 on December, 31st 1987. The longest data set available from NYSE-Euronext begins from January, 5th 1962; however, from this date to September, 13th 1968, the frequency of the stock index is weekly. For this reason, we choose to begin the period study from September, 30, 1968 until the end of year 2008. We note the presence of stock index return autocorrelation for any given lag; in addition, we observe the presence of strong

\footnotetext{
${ }^{5}$ I would like to thank Professor Michel Fleuriet who provided me with the data set.
} 
heteroskedasticity according the Q-statistics. This study makes use of filtered daily data ${ }^{6}$ in order to apply EVT techniques to iid observations given that the fat-tailedness of returns stems from the fat-tailedness of innovations.

\subsection{Data filtering process}

We examine all the possible specifications within five lags. We test 25 specifications of $\operatorname{ARMA}(\mathrm{p}, \mathrm{q})$ models with $p=1, \ldots, 5$ and $q=1, \ldots, 5$ in addition to 25 specifications with $\operatorname{ARMA}(\mathrm{p}, \mathrm{q})+\operatorname{GARCH}(1,1)$. We select the more parsimonious model. Four criteria are used for comparison: the log-likelihood value, the Akaike criterion, the autocorrelogram of residuals and squared residuals and the ARCH effect test. We take care of the trade off between parsimony and maximizing criteria. We find that the $\operatorname{ARMA}(2,4)+\operatorname{GARCH}(1,1)$ model produces the best fit. We then test an alternative model that allows for leverage effects by considering the contribution of the negative residuals in the ARCH effect. The $\operatorname{ARMA}(2,4)+\mathrm{TGARCH}(1,1)$ model improved the fit in all considered criteria. Define the market log-returns as $\left\{R_{t}\right\}_{t=1, \ldots, T}$ with $\mathrm{T}=$ 10,017 daily observations. The $\operatorname{ARMA}(2,4)+$ TGARCH $(1,1)$ specification is then given as follows

$$
R_{t}=\mu+\sum_{i=1}^{2} \phi_{i} R_{t-i}+\sum_{i=1}^{2} \theta_{i} \epsilon_{t-i}+\epsilon_{t}
$$

with the innovations $\epsilon_{t}$ being functions of $Z_{t}$ and $\sigma_{t}$

$$
\epsilon_{t}=Z_{t} \sigma_{t}
$$

where the standardized returns $Z_{t}$ are independent and identically distributed, such as:

$$
Z_{t} \hookrightarrow F_{Z}(0,1)
$$

where $F_{Z}$ is an unknown distribution of $Z$. The purpose of the timevarying $\sigma_{t}$ is to capture as much of the conditional variance in the residual $\epsilon_{t}$ in order to leave $Z_{t}$ approximately iid

$$
\sigma_{t}^{2}=\omega+\alpha\left(Z_{t-1} \sigma_{t-1}\right)^{2}+\gamma\left(Z_{t-1} \sigma_{t-1}\right)^{2} I_{Z_{t-1} \sigma_{t-1}<0}+\beta \sigma_{t-1}^{2}
$$

\footnotetext{
${ }^{6}$ Filtering processes on high frequency financial data are discussed among others by Dacorogna et al. (2001), Breymann, Dias and Embrechts (2003).
} 
As the MA(1) term is not statistically significant, we remove it from the model and set $\theta_{1}=0$. The results for the maximum likelihood estimation of this model are displayed in Table 1 . This model provides very good fit according to the selected criteria; all the model's parameters are highly statistically significant. We therefore extract the maxima and minima from the return shocks $\left\{Z_{t}\right\}_{t=1, \ldots, T}$ corresponding to standardized demeaned return series using a time-varying volatility model. Figure 1 shows the evolution of the CAC 40 stock index (1) prices, (2) volatility, (3) raw returns and (4) standardized returns. Our discussion is hereafter restricted to the standardized return maxima $+Z$ and minima $-Z$.

\subsection{Crash event detection}

The filtering process contributes to answer the question of how to identify a crash event from the past. Indeed, from an economic perspective, it corresponds to a transformation of daily raw returns into daily standardized (devolatized) returns. This transformation helps to identify tail events independent of the associated volatility regime. It is clear that this transformation allows the disentanglement of a crash from another tail event, whose magnitude may be amplified by the high level of volatility. More generally, according to our hypothesis, the stock market crash requires being:

Sudden It means a price variation independent of the current volatility regime. It refers to a high-return shock during a period of low volatility and not to a small-return shock during a period of high volatility. Given that standardized returns $Z_{t}$ are independent and are identically distributed, such as $Z_{t} \hookrightarrow F_{Z}(0,1)$, we have

$$
\forall t \in[1, \ldots, T], Z_{t}=\min \left(Z_{1}, \ldots, Z_{T}\right)
$$

Significant It means a price variation whose magnitude is high. This magnitude effect can be captured by a jump in the volatility process. Indeed, asymmetric volatility is a striking phenomenon in equity markets. More precisely, the so-called leverage effect characterized a negative relation between past realized returns and conditional volatility. Therefore, a decline in realized returns will be followed by an asymmetric increase in the conditional volatility. In addition, volatility of stock price changes is directly related 
to the rate of flow of information (e.g. Ross (1989), Maheu and McCurdy (2004)). This jump volatility effect can be given by

$$
\forall t \in[1, \ldots, T], \frac{\sigma_{t+1}}{\sigma_{t}}=\max \left(\frac{\sigma_{2}}{\sigma_{1}}, \ldots, \frac{\sigma_{T}}{\sigma_{T-1}}\right)
$$

International crash: It induces contagion effect throughout international financial markets, increasing the stock market index correlation level. A leading U.S stock index such as the S\&P 500 can be considered as a benchmark for international correlation measure. The conditional correlations are derived indirectly, in multivariate GARCH models, from the ratio of the covariance and the product of the roots of the conditional variances ${ }^{7}$. However, various multivariate GARCH specifications remain cumbersome. Engle (2002) proposes a Dynamic Conditional Correlation model (DCC) with a two step procedure; the first step requires the GARCH variances to be estimated univariately. Their parameter estimates remain constant for the next step; the second step parameterizes the conditional correlations directly and maximizes the log-likelihood function. Engle (2002) finds that DCC model is often the most accurate among the multivariate GARCH model family. The contagion effect is given by

$$
\forall t \in[1, \ldots, T],\left|\rho_{t+1}-\rho_{t}\right|=\max \left(\left|\rho_{2}-\rho_{1}\right|, \ldots,\left|\rho_{T}-\rho_{T-1}\right|\right)
$$

where $\rho$ is the time varying conditional correlation level between conditional volatility changes of the French CAC 40 stock index and the S\&P 500 stock index. Even if we introduce the definition of a domestic crash, it sounds intuitive that a crash should induce systemic risk.

Domestic crash:

$$
\forall t \in[1, \ldots, T],\left|\rho_{t+1}-\rho_{t}\right| \approx 0
$$

${ }^{7}$ Given the pair $\left\{Z, Z^{\prime}\right\}$ of standardized returns referring respectively to the CAC 40 stock index and the S\&P 500 stock index, $\rho_{Z, Z^{\prime}, t}$ is the conditional correlation level, $\sigma_{Z, Z^{\prime}, t}$ is the conditional covariance level, and $\left\{\sigma_{t}^{2}, \sigma_{t}^{2}\right\}$ are the respective conditional variances of $Z$ and $Z^{\prime}$. The time-varying conditional correlation is therefore given by $\rho_{Z, Z^{\prime}, t}=\sigma_{Z, Z^{\prime}, t} / \sqrt{\sigma_{t}^{2} \sigma_{t}^{\prime 2}}$. In our case, we consider the time-varying conditional correlation between conditional volatility logarithmic changes of $Z$ and $Z^{\prime}$ respectively denoted $\left\{\log \left(\frac{\sigma_{t}}{\sigma_{t-1}}\right), \log \left(\frac{\sigma_{t}^{\prime}}{\sigma_{t-1}^{\prime}}\right)\right\}$. Results provided upon request. 


\section{One-day time period}

$$
\forall t \in[1, \ldots, T], \delta_{t}=1 / 252 .
$$

\subsection{Return transformation}

The reverse transformation for computing raw returns from standardized returns is also very useful for understanding the economic meaning of the statistical inference drawn from standardized return series analyses. Indeed, many articles applying EVT to standardized returns leave the reader with few economic interpretations of the results extracted from the filtered series. Therefore, we need to transform the standardized returns into "equivalent raw returns". As recent literature, to our knowledge, does not propose any solution, this article proposes a linear transformation based on a semi-parametric technique that extends the ordinary least squares regression model to conditional quantiles. Indeed, while the great majority of regression models are concerned with analyzing the conditional mean of a dependent variable (standard ordinary least squares); quantile regression (Koenker and Bassett (1978)) permits a more complete description of the conditional distribution. It can be used to measure the effect of covariates, not only in the center of a distribution, but also in the upper and lower tails. Therefore, quantile regression is the ideal tool for estimation of conditional quantiles of a response (raw return), given a vector of covariates (standardized returns). As a consequence, a quantile regression is implemented ${ }^{8}$ for the left tail and another one for the right tail. The choice of the percentile level corresponds exactly to the respective selected threshold levels for each tail, which are computed in section 3.6. This complementary methodology refers to the augmented extreme value theory approach.

\footnotetext{
${ }^{8}$ The linear conditional quantile function can be estimated by solving $\hat{\beta}_{n_{u}}(q)=$ $\operatorname{argmin}_{\beta(q)}\left\{\sum_{i=1}^{n} \varsigma_{q}\left(R_{i}-Z_{i} \beta(q)\right\}\right)$ where the check function which weights positive and negative values asymmetrically for any quantile $0<q<1$ is $\varsigma_{q}(v)=v(q-I(v<0))$ where $I($.$) denotes the indicator function. For the left tail (respectively the right tail),$ the intercept is -0.0047 (respectively 0.0033 ), the slope coefficient is 0.0105 (respectively 0.0099). The parameters are all statistically significant at the level of $1 \%$. The adjusted r-squared value is 0.5715 (respectively 0.6082). The sum of squares errors between raw returns and equivalent raw returns is $9.15 \%$ (respectively $10.86 \%$ ). Details are given upon request.
} 


\subsection{Descriptive statistics of filtered data}

Table 1 presents the descriptive statistics of the devolatized log-returns. The D'Agostino (1970) test of skewness (DAST) under the null hypothesis of normality supports the alternative hypothesis of skewness with a p-value of less than 2.2e-16. The Anscombe-Glynn (1983) test of kurtosis (AGKT) under the null hypothesis of normality supports the alternative hypothesis of a kurtosis different from three, with a p-value of less than 2.2e-16. This statistic measures the heaviness of the tails relative to normal distribution. In all cases, the Jarque-Bera statistics yield a strong rejection of the normality hypothesis. Next, we consider various percentiles from $1 \%$ to $99 \%$ as comparisons with those implied by the normal distribution. Again, we have a departure when comparing the empirically extreme one percentile with the 2.3263 critical value of the normal distribution. This means that such a realization would have no probability of existing in a Gaussian framework. The Q-statistic for a given lag is a test statistic for the null hypothesis, where there is no autocorrelation up to the given order. For 5 and 10 lags, the Q-statistic is distributed as a $\chi_{5}^{2}, \chi_{10}^{2}$ and $\chi_{20}^{2}$ with $95 \%$ critical values of 11.07, 18.31 and 31.41. The correlogram for the filtered series shows no more dependence because the Q-statistics for the series are lower than the critical values. Short-term serial dependence remains significantly below the confidence interval at 95\%. Engle's Lagrange multiplier (LM) test statistic measures the ARCH effect in the residuals. It computes the number of observations times the $R^{2}$ from the test regression of the squared residuals, on constant and lagged squared residuals up to a given order $q$. The LM test statistic is asymptotically distributed $\chi_{q}^{2}$ under general conditions. The null hypothesis underlying this test assumes that there is no $\mathrm{ARCH}$ up to order $q$ in the residuals. There is no more evidence of remaining ARCH effects at any lag.

\section{Empirical results}

\subsection{Threshold selection}

Threshold selection is usually arbitrarily limited to one method in most of the literature, while there are many approaches that can be complementary. In this article, we propose a complete approach for threshold detection, mixing visual inspection and automatic selection. The sample mean excess func- 
tion allows for distinction between thin- and heavy-tailed distributions; the heavy-tailed distribution is associated with a positive slope. We compute the mean residual life plot (MRLP), which is an estimate of the mean excess function. The threshold detection is done by choosing the smallest observation, to the right of which the mean excess function remains approximately linear as a function of the ordered data. Figure 2 displays the mean residual life plot. The critical threshold, above which the slope is positive, is around +1.0 for $+Z$ and -1.50 for $-Z$. From this level, the sample mean excess function increases linearly as the threshold increases. This signifies entrance into a tail area. The threshold plot exposes the stability region of the tail index parameter and is presented in Figure 3. An investigation of the stability of the tail index parameter is checked by implementing the General Pareto distribution over a possible range of thresholds. Even if we note a relative instability, a possible range of stability belongs in an interval of +1.0 and +2.0 for $+Z$, while it is between -0.50 and -1.50 for $-Z$. For the optimal threshold detection, we follow Beirlant et al. (2004), who propose a criterion for which the AMSE of the Hill estimator of the extreme value index is minimal for the optimal number of observations in the tail. Optimal threshold selection yields estimates very close to the mean residual life plot. The optimal threshold ${ }^{9}$ is around +0.95 (or the $84.80^{\text {th }}$ percentile) for $+Z$ and -1.38 (or (1-0.9246) i.e., $7.54^{\text {th }}$ percentile) for $-Z$. It corresponds, respectively, to a number of upper order statistics of 1,522 and 755 out of 10,014 observations. The threshold values computed from the optimal algorithm respond to the criteria of stability and sufficient exceedances with minimum variance. Table 2 summarizes the results for the threshold selection. Due to the convergence between the three approaches, we consider the threshold optimal values in this study.

\subsection{Tail area detection}

The critical threshold of +0.95 for $+Z$ and -1.38 for $-Z$ corresponds to the entry point of the right and left tail standardized distributions. Applying the return transformation from the standardized returns into equivalent raw returns will give us virtual location entry points for the left and right tails.

\footnotetext{
${ }^{9}$ The same approach applied directly on raw returns gives for the right tail a threshold of $+1.07 \%$ (upper order statistics of 1406) and for the left tail a threshold of $-3.95 \%$ (upper order statistics of 71). Results provided upon request.
} 
Indeed, the threshold for the right tail becomes $+1.28 \%$ (upper order statistics of 1,013) and for the left tail becomes $-1.92 \%$ (upper order statistics of 444). This means approximately that beyond $+1.5 \%$ and below $-2.0 \%$, the French CAC 40 stock index enters into tail areas. This threshold selection is required for the GPD estimation. Table 3 displays the results for the GPD when considering the optimal threshold values. The maximum likelihood estimators of the GPD are the values of the two parameters $(\hat{\xi}, \hat{\sigma})$ that maximize the log-likelihood. The tail index value of +0.1439 for $-Z$ is statistically significant, in contrast to that of $+Z$. The positive sign confirms the presence of fat-tailedness for the lower tail. Indeed, the larger the tail index, the more fat-tailed the distribution. This tail index value indicates that the CAC 40 standardized returns stem from a distribution with finite variance, skewness, and kurtosis. The upper tail has a tail index close to zero, indicating moderate tail behavior belonging to the Gumbel-type domain of attraction. These results are fully consistent with the Q-Q plots of Figure 4. The scale parameters of $+Z$ and $-Z$ are statistically significant and with the same dispersion.

\subsection{Crash event identification}

The Table 4a reveals that the 1981-05-13 event is the biggest crash of the sample with a standardized return of $-11.66 \%$. It is consistent with results reported in Table 4b. The next day, the volatility reaches its highest level ever at $95 \%$. The contagion effect remains relatively high despites its domestic origin. The 1991-08-19 event is the second biggest crash of the sample. They can be visually identified in Figure 1 (lower right corner); the second crash does not appear in the raw returns graph (lower left corner); this means that relying on raw returns to identify crashes turns out to be misleading; these two first order crashes correspond to a natural cut-off; in addition, they both have a political connotation. The 1989-10-16 event is the third biggest crash of the sample. These two events do not appear in table $4 \mathrm{~b}$ because their impact is relatively limited in time. The 2007-02-27 event is the eighth biggest crash for which the correlation with the U.S. market is the highest of the sample; this date marks the beginning of the subprime crisis. The 2008-01-21 event is the tenth biggest crash; the U.S. market was closed at that date. These two dates are the only crash events from the recent banking

crisis. In fact, most of the extreme returns that occurred in 2007 and 2008 are due to a high regime of volatility. Indeed, the CAC 40 implied (historical) 
volatility is about $31.44 \%(35.40 \%)$ in 2008 versus $19.43 \%(17.13 \%)$ in 2007 and $22.67 \%$ (20.55\%) from 2000 to 2007; actually, 2008 is the most volatile year of the sample. As a consequence, this 2008 financial year appears to be more volatile than extreme. For instance, Table 4 a gives an example of the over-representation of year 2008 in terms of lowest raw returns and highest volatilities. Precisely, 21 (50) out of the 100 lowest raw returns (highest volatilities) of the sample belong to year 2008. The 2001-09-11 event is the eleventh biggest crash; the U.S. market was closed at that date. The 198705-15 event is the twelfth biggest crash; this date corresponds to a percursor of the 19 October 1987 . The remaining negative standardized returns have very low contagion effect (rank $>100$ ); as a consequence, we can limit the number of crashes as 12 among 755 negative tail events.

\subsection{Tail event forecasting}

Table 5 displays some tail-related risk measures, such as the value at risk and expected shortfall measures, for both Gaussian and General Pareto distributions. Probability levels of $99 \%, 99.5 \%, 99.9 \%, 99.95 \%$ and $99.99 \%$ are considered. The distance between the GPD and Gaussian measures increases with the level of probability. The conservative choice of the 0.9999 probability level corresponds to a worst possible movement in 10,000 days, or approximately 40 years. The reported $0.01 \%-\mathrm{GPD}-\mathrm{VaR}$ is $-6.94 \%$ and the $0.01 \%$-GPD-ES is $-8.46 \%$. This corresponds to transformed returns of $-7.78 \%$ for the $0.01 \%$-GPD-VaR and $-9.39 \%$ for the $0.01 \%$-GPD-ES. It means that the prediction at the $99.99 \%$ level cannot predict the magnitude of the two lowest standardized returns. Both of them have a political connotation (see Table 4a). Figure 6 is the associated tail plot in log-log scale. Table 6 displays the return levels for both positive and negative standardized residuals with confidence intervals. We note, unsurprisingly, that the return levels for negative returns are higher in comparison to the positive ones; it confirms the asymmetric nature of the distribution. Figure 5 shows the associated plots. The return level plot consists of plotting the theoretical quantiles as a function of the return period with a logarithmic scale for the x-axis. It shows the profile log-likelihood curve of the 100-year return level with the $95 \%$ confidence intervals. It corresponds to a $-8.21 \%$ standardized return with an asymmetric confidence interval. The $95 \%$ confidence interval is obtained from the profile of log-likelihood as [-9.98\%, -6.44\%]. This corresponds to an equivalent raw return of $-9.13 \%$ with a $95 \%$ confidence interval of $[-10.99 \%$, 
$-7.26 \%$ ]. The level expected to be exceeded once every century is therefore $-9.13 \%$; its lower bound is $-10.99 \%$.

\subsection{Result summary}

1) The tail area begins from $+1.5 \%$ for the right tail and $-2.0 \%$ for the left tail.

2) The CAC 40 stock returns distribution has an asymmetric nature: left tail distribution has a General Pareto form and right tail distribution is exponential.

3) Tail-related risk measures, such as the value at risk and expected shortfall based on a General Pareto distribution, can capture the magnitude of the 2007-2008 extreme events at the $0.01 \%$ associated probability level. The $0.01 \%$-GPD-VaR level is $-7.78 \%$ and the $0.01 \%$-GPD-ES is $-9.39 \%$. In addition, the theoretical daily loss, which should be exceeded in one year every century, is $-10.99 \%$.

4) Over the 40-year period, 12 crashes are identified (2 in 2007-2008) in comparison with 755 negative tail events; in addition, the 2007-02-27 marks the beginning of the subprime crisis.

5) The magnitude of the recent banking crisis is very important in terms of raw returns because the French market experienced its highest level of volatility in 2008 .

\section{Conclusion}

The goal of this article is to disentangle crashes from negative extreme returns with a risk management stand point. The modus operandi is based on an augmented extreme value theory approach. An application to the French stock market is provided using the longest daily time series ever used (1968-2008). The general contribution is to test a definition of stock market crashes that is risk management-oriented, while the empirical contributions are three-fold:

First, an econometric specification is proposed for the French data over the 40-year period. From 50 possible candidates, the $\operatorname{ARMA}(2,4)$-TGARCH $(1,1)$ structure appears to offer the best fit for explaining the return-generating process over the long run. 
Second, both visual inspection techniques and recent automated threshold selection procedures are applied to identify the tail region of the standardized returns. This represents one of the most complete approaches for threshold selection.

Third, a return transformation method for converting standardized returns into equivalent raw returns is developed; it is based on a quantile regression technique, in order to offer economic interpretation of the empirical results. Finally, the policy-oriented conclusion is that the identification of the crash event of 2007 (2007-02-27) might have justify the bailout plan of Lehman Brothers and avoid the crisis spread. 


\section{References}

[1] Acerbi, C., 2002. Spectral measures of risk: A coherent representation of subjective risk aversion. Journal of Banking and Finance 26, 1505-1518.

[2] Agostino D', R.B., 1970. Transformation to normality of the null distribution of G1. Biometrika 57, 679-681.

[3] Anscombe, F.J. and Glynn W.J., 1983. Distribution of kurtosis statistic for normal statistics. Biometrika 70, 227-234.

[4] Artzner, P., Delbaen, F., Eber, J., and Heath, D., 1999. Coherent measure of risk. Mathematical Finance 9, 203-228.

[5] Bali, T.G. and Neftci, S.N., 2002. Disturbing extremal behaviour of spot rate dynamics. Working paper, ISMA Center, University of Reading.

[6] Balkema, A. A. and de Haan L., 1974. Residual life time at great age. Annals of Probability 2, 792-804.

[7] Bao Y., Lee T-H, Saltoglu B., 2006. Evaluating predictive performance of Value-atRisk models in emerging markets: a reality check. Journal of Forecasting 25, 101-128.

[8] Beirlant, J., Vynckier P. and Teugels J., 1996. Practical Analysis of Extreme Values. Leuwen University Press.

[9] Beirlant J., Teugels J., Goegebeur Yu., and Segers J., 2004. Statistics of Extremes: Theory and applications. Wiley, New York.

[10] Bekaert G. and Wu G., 2000. Asymmetric volatility and risk in equity markets. Review of Financial Studies 13, 1-42.

[11] Black, F., 1976. Studies in stock price volatility changes, American Statistical Association, Proceedings of the Business and Economic Statistics Section, 177-181.

[12] Breymann, W., Dias, A., Embrechts, P., 2003. Dependence structures for multivariate high-frequency data in finance. Quantitative Finance 3, 1-16.

[13] Campbell, J. Y. and Hentchel L., 1992. No news is good news: An asymmetric model of changing colatility in stock returns. Journal of Financial Economics 31, 281-318.

[14] Christoffersen P.F., Diebold F.X., and Schuermann T., 1998. Horizon problems and extreme events in financial risk management. Working Paper, University of Pennsylvania.

[15] Coles S., 2001. An Introduction to Statistical Modeling of Extreme Values. Springer, New York.

[16] Dacorogna, M., Pictet O., Muller U., and de Vries C.G., 1994. The distribution of a extremal foreign exchange rate returns in extremely large datasets. Working paper, Olsen \& Associates.

[17] Dacorogna M., Gencay R., Muller U., Olsen R., and Pictet O., 2001. An Introduction to High-Frequency Finance. Academic Press, San Diego, CA. 
[18] Danielsson J. and de Vries C.G., 1997. Tail index quantile estimation with very high frequency data. Journal of Empirical Finance 4, 241-257.

[19] Danielsson J. and Morimoto Y., 2000. Forecasting extreme financial risk: A critical analysis of practical methods for the Japanese market. Monetary and Economic Studies 12, 25-48.

[20] Danielsson J., de Haan L., Peng L., and de Vries C.G., 2001. Using a bootstrap method to choose the sample fraction in tail index estimation. Journal of Multivariate Analysis 76, 226-248.

[21] Danielsson J., Jorgensen B.N., Samorodnitsky G., Sarma M., de Vries C.G., 2005. Subadditivity re-examined: the case for value-at-risk. Working paper, Cornell University.

[22] De Sousa, B. and Michailidis G., 2004. A diagnostic plot for estimating the tail index of a distribution. Journal of Computational and Graphical Statistics 13, 974-995.

[23] Diebold, F.X., Schuermann T., and Stroughair J., 1999. Pitfalls and Opportunities in the Use of Extreme Value Theory in Risk Management, in: A.-P. N. Refenes, J.D. Moody and A.N. Burgess (eds.), Advances in Computational Finance, Kluwer, Amsterdam, pp 3-12.

[24] Embrechts P., Klüppelberg C., and Mikosch T., 1997. Modelling Extremal Events for Insurance and Finance. Springer, New York.

[25] Engle R., 2002, Dynamic conditional correlation: A simple class of multivariate generalized autoregressive conditional heteroskedasticity models. Journal of Business and Economic Statistics 20, 339-350.

[26] Gabaix X., Gopikrishnan P., Plerou V., and Stanley H.E., 2003. A theory of powerlaw distributions in financial market fluctuations. Nature 423, 267-270.

[27] Gabaix X., Gopikrishnan P., Plerou V., and Stanley H.E., 2005. Are Stock Market Crashes Outliers? Working paper, MIT, NBER.

[28] Gallais-Hamonno G. and Arbulu P., 2002. Valeurs extrêmes et changements d'appréciation du risque à la bourse de Paris sur deux siècles, 1802-2000. Finance $2,145-176$.

[29] Gençay R., Selçuk F., and Ulugülyagci A., 2003. High volatility, thick tails and extreme value theory in value-at-risk estimation. Insurance Mathematics and Economics $33,337-356$.

[30] Gettinby G., Sinclair C.D., Power D. M., and Brown R.A., 2006. An analysis of the distribution of extremes in indices of share returns in the US, UK and Japan from 1963 to 2000. International Journal of Finance and Economics 11, 2, 97-113.

[31] Gilli M., and Kellezi E, 2000. Extreme value theory for tail-related risk measure. Working paper, University of Geneva.

[32] Gumbel EJ., 1941. The return period of flood flows. Annals of Mathematical Statistics 12, 163-190. 
[33] Gumbel E.J., 1958. Statistics of Extremes, Columbia University Press, New-York.

[34] Hall, P. and Welsh A.H., 1985. Limit theorems for the median deviation. Annals of the Institute of Statistical Mathematics 37, 27-36.

[35] Hall, P., 1990. Using the bootstrap to estimate mean squared error and select smoothing parameters in nonparametric problems. Journal of Multivariate Analysis 92, 177203.

[36] Hill, B.M., 1975. A simple general approach to inference about the tail of a distribution. Annals of Statistics 3, 1163-1174.

[37] Inui, K. and Kijima M., 2005. On the significance of expected shortfall as a coherent risk measure. Journal of Banking and Finance 29, 853-864.

[38] Jondeau, E. and Rockinger M., 2003. Testing for differences in the tails of stock market returns. Journal of Empirical Finance, 10, 559-581.

[39] Koenker, R. and Bassett G., 1978. Regression quantiles. Econometrica 46, 33-50.

[40] Kuester, K., Mittik S., and Paolella M.S., 2005. Value-at-risk prediction: A comparison of alternative strategies. Journal of Financial Econometrics 4, 53-89.

[41] LeBaron B. and Samanta R., 2004. Extreme value theory and fat tails in equity markets. Working paper, Brandeis University.

[42] Le Bris D., 2008. What is a stock market crash? 20 French crashes since 1854. Working paper, University of Paris-Sorbonne.

[43] Le Bris D., and Hautcoeur P-C., 2008. Challenge to triumphant optimists? A new index for the Paris stock-exchange (1854-2007). Working paper, University of ParisSorbonne, Paris School of Economics.

[44] Longin, F., 1993. Booms and crashes: Application of extreme value theory to the U.S. stock market. Working paper, London Business School.

[45] Longin F., 1996. The asymptotic distribution of extreme stock market returns. Journal of Business 69, 383-408.

[46] Longin F., Boulier J-F., and Dalaud R., 1998. Application de la théorie des valeurs extrêmes aux marchés financiers. Banque et Marchés 32, 5-14.

[47] Longin, F., 2001. Stock market crashes: some quantitative results based on extreme value theory. Derivatives Use, Trading \& Regulation 7, 197-205.

[48] Maheu J.M. and McCurdy T.H., 2004. News arrival, jump dynamics, and volatility components for individual stock returns. Journal of Finance 59,755-793.

[49] Mandira S., 2004. Characterization of the tail behavior of financial returns: An empirical study from India's stock market. Working paper, EURANDOM, the Netherlands.

[50] Martinz, F.C., and Yao F., 2006. Estimation of value-at-risk and expected shortfall based on nonlinear models of return dynamics and extreme value theory. Studies in Nonlinear Dynamics and Econometrics 10, 107-149. 
[51] McNeil A.J., 1997. Estimating the tails of loss severity distributions using extreme value theory. ASTIN Bulletin, 27: 117-137.

[52] McNeil, A.J., and Saladin T., 1998. Developing Scenarios for Future Extreme Losses Using the POT Model, Extremes and Integrated Risk Management. RISK books, London.

[53] McNeil A.J., 1999, Extreme value theory for risk managers. Working Paper, University of Zurich.

[54] McNeil, A.J., Frey, R., 2000. Estimation of tail-related risk measures for heteroskedastic financial time series: an extreme value approach. Journal of Empirical Finance 7, 271- 300.

[55] Ozun A., Cifter A., and Yilmazer S., 2007. Filtered extreme value theory for valueat-risk estimation. Working paper, Marmara University.

[56] Pickands J.I., 1975. Statistical inference using extreme value order statistics. Annals of Statistics 3, 119-131.

[57] Robert, C., 1998. Mouvements extrêmes des séries financières haute fréquence. Finance 19, 221-247.

[58] Shiller R.J., 1988. Causes of changing financial market volatility. Proceedings, Federal Reserve Bank of Kansas City, 1-32.

[59] Ross, S.A., 1989. Information and volatility: The no-arbitrage martingale approach to timing and resolution irrelevancy. Journal of Finance 44, 1 Ŭ17.

[60] Smith, R., 1987. Estimating tails of probability distributions. Annals of Statistics 15, 1174-1207.

[61] Tolikas, K., and Brown R.A., 2005. The distribution of the extreme daily returns in the Athens stock exchange. Working paper, University of Dundee.

[62] Yamai, Y., and Yoshiba, T., 2005. Value-at-risk versus expected shortfall: A practical perspective. Journal of Banking and Finance 29, 997-1015. 
Figure 1: CAC 40 stock index

Figure 1 displays graphics from CAC 40 stock index from September, 30th 1968 to December 31st 2008. From upper left to lower right corner: CAC 40 stock index prices, TGARCH volatility, raw returns and standardized returns.
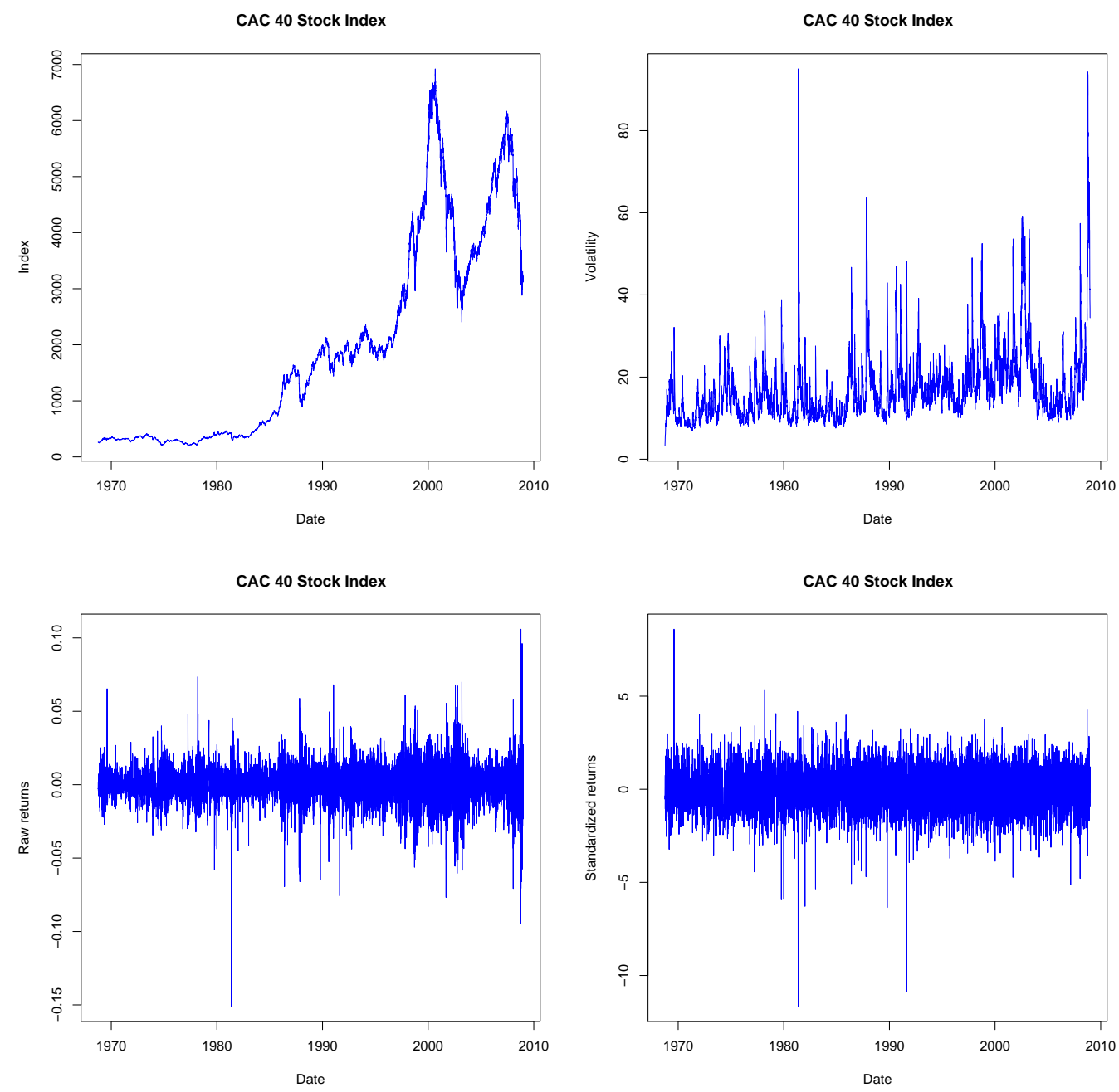
Figure 2: Mean residual life plot

Figure 2 displays the mean excess function plot of the upper $(+Z)$ and lower tail $(-Z)$ of the CAC 40 stock index standardized returns. The mean residual life plot is flat for the exponential distribution. When the plot is approximately linear with positively sloped, it indicates Pareto behavior in the tail. This plot is used to select an appropriate threshold value.
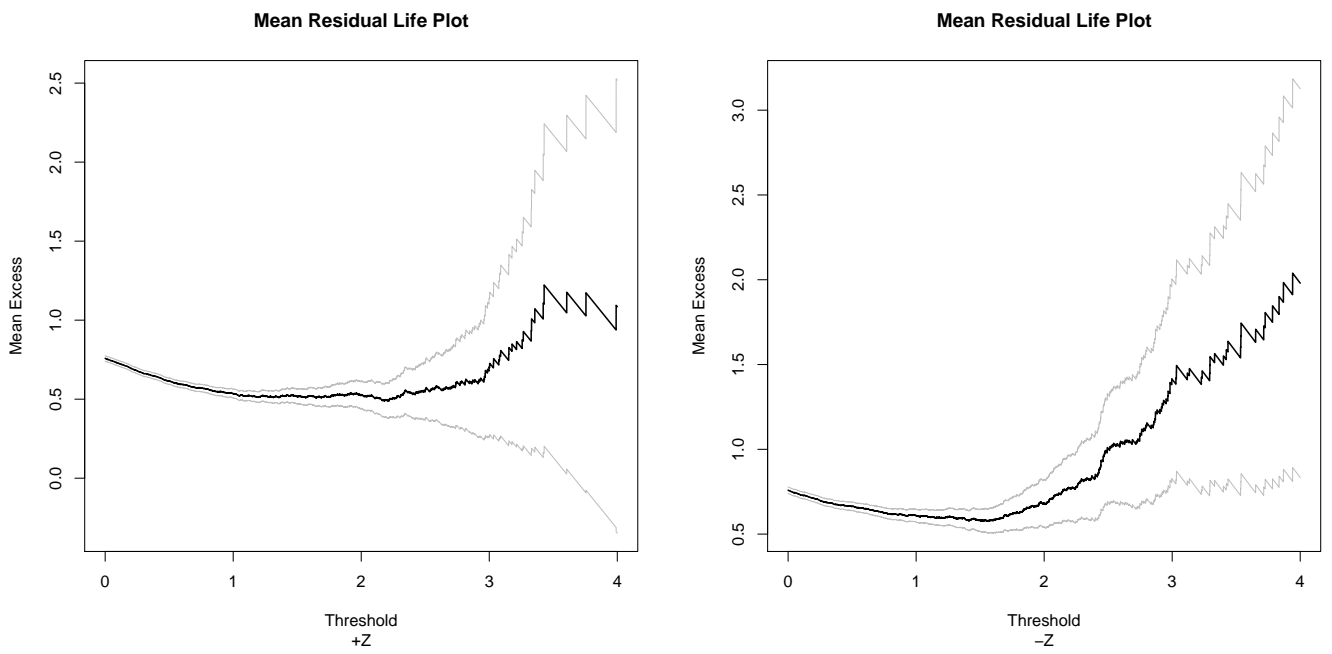


\section{Figure 3: Stability plot}

Figure 3 displays thresholds plots for the upper tail $(+Z)$ and lower tail $(-Z)$ of the CAC 40 stock index standardized returns. The maximum likelihood estimates for the tail index $\xi$ are plotted against a range of thresholds with $95 \%$ confidence limits. The stability in the parameter estimates can be checked. The plot is used to select an appropriate threshold for which the parameter estimates are approximately constant above the threshold range.
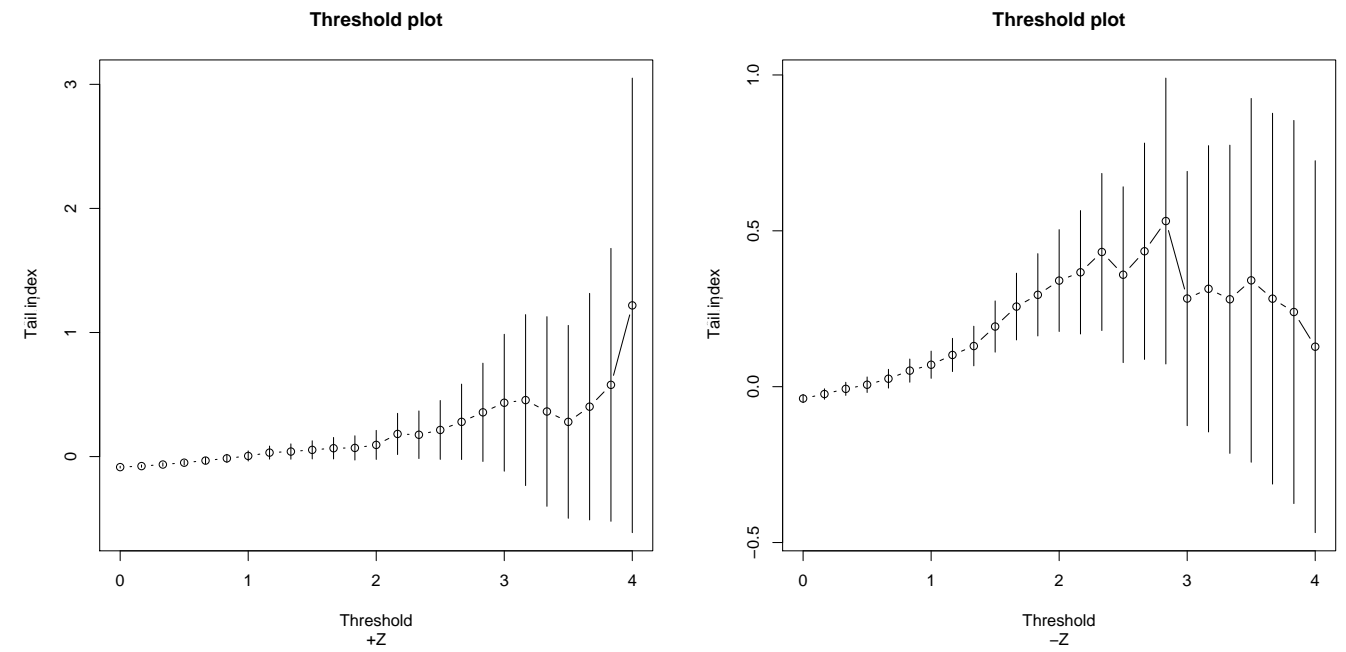


\section{Figure 4: Quantile-Quantile plot}

Figure 4 displays the QQ-plot of the upper $(+Z)$ and lower tail $(-Z)$ of the CAC 40 stock index standardized returns. The QQ-plot compares the observed quantiles with the theoretical ones. If the standardized returns follow an exponential distribution then we should observe a linear trend. We note a strong concave departure in the QQ-plots that is a sign of the presence of heavy tails.
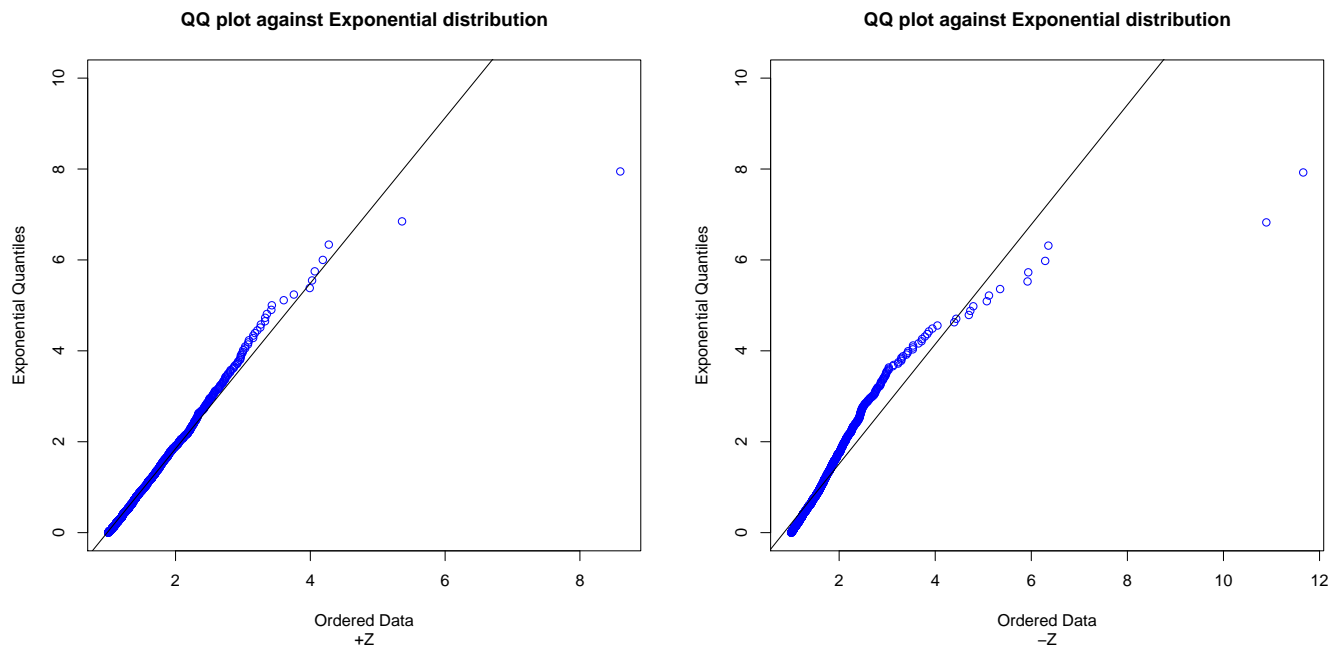


\section{Figure 5: Return level plot}

Figure 5 displays two return level plots for the lower tail $(-Z)$ of the CAC 40 stock index standardized returns. The plot in the left hand side is based on the computation of the $1,2,5,10,20,50$ and 100-year return levels for the fitted GPD with $95 \%$ confidence intervals computed by the delta method. The plot in the right hand side shows the profile log-likelihood curve of the 100-year return level with the $95 \%$ confidence intervals located in the points of intersection. In contrast with the delta method, the confidence intervals are asymmetric about the maximum likelihood estimate. More precisely, the profile likelihood interval is shifted to the right showing an asymmetry with the increasing return level since the data provide weaker information on high levels.
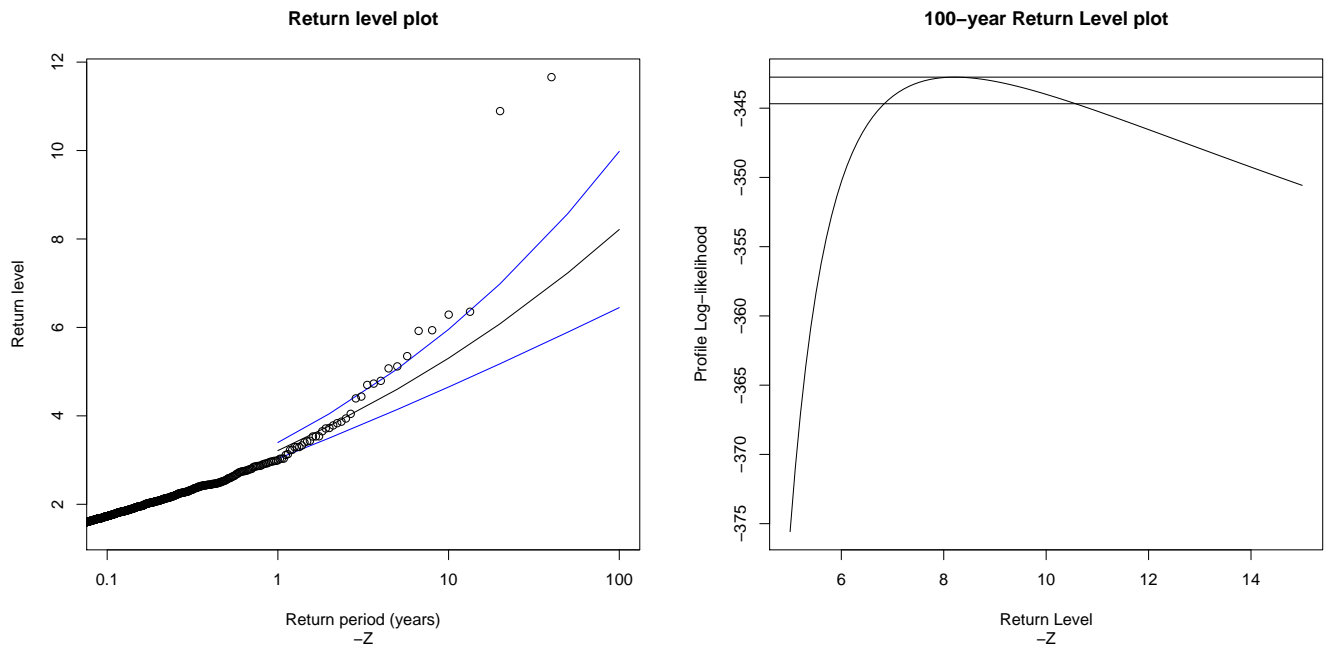
Figure 6: Tail plot

Figure 6 displays the CAC 40 stock index standardized negative returns $(-Z)$. The tail plot is based on a generalized Pareto model fitted to losses over the $-Z$-threshold. The estimated model is plotted as a solid line while the actual daily $-Z$ above the threshold are shown in circles. The left y-axis indicates the tail probabilities $1-F(x)$ and the lower $\mathrm{x}$-axis indicates the $-Z$ values (in logarithmic scale). The vertical three lines (from left to right) locate the 0.99th, 0.995th, 0.999th and 0.9999th Expected Shortfall level.

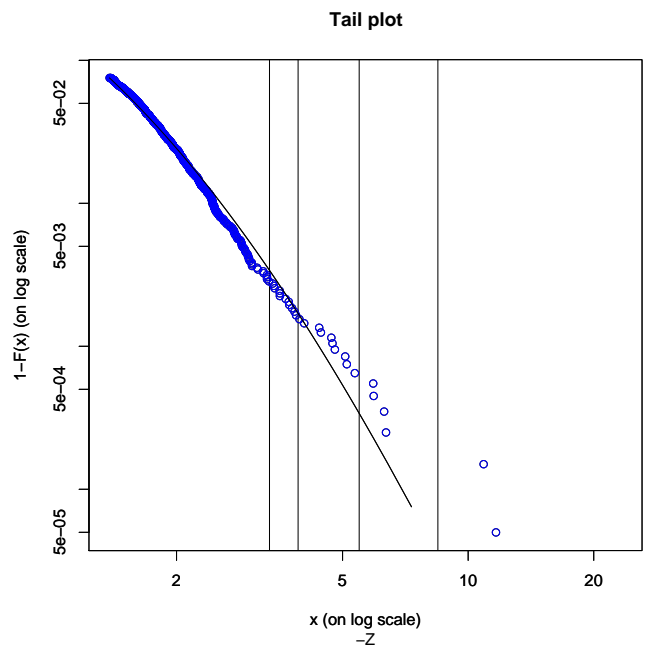




\section{Table 1: Descriptive statistics}

Table 1 presents the descriptive statistics of the CAC 40 stock index standardized daily log-returns (Z) from September, 30th 1968 to December 31st 2008. The filtered model is an $\operatorname{ARMA}(2,4)$-TGARCH $(1,1)$.

\begin{tabular}{|c|c|c|c|}
\hline & $Z$ & & $Z$ \\
\hline Mean & -0.0011 & $\begin{array}{r}\text { Q10 (residual) } \\
(\mathrm{p}-\text { value })\end{array}$ & $\begin{array}{r}8.8759 \\
(0.114)\end{array}$ \\
\hline Median & -0.0015 & $\begin{array}{r}\text { Q10 (squared residual) } \\
(\mathrm{p}-\text { value })\end{array}$ & $\begin{array}{l}3.0381 \\
(0.694)\end{array}$ \\
\hline Maximum & 8.5990 & $\begin{array}{r}\mathrm{Q} 20(\text { residual }) \\
(\mathrm{p}-\text { value })\end{array}$ & $\begin{array}{r}17.046 \\
(0.316)\end{array}$ \\
\hline Minimum & -11.6598 & $\begin{array}{r}\text { Q20 (squared residual) } \\
(\mathrm{p}-\text { value })\end{array}$ & $\begin{aligned} 12.034 \\
(0.676)\end{aligned}$ \\
\hline Std.Dev. & 0.9999 & $\begin{array}{r}\text { EngleLM(1) } \\
\text { (Probability) }\end{array}$ & $\begin{array}{r}0.5133 \\
(0.4737)\end{array}$ \\
\hline $\begin{array}{r}\text { Skewness } \\
(\mathrm{z}-\text { statistic, } \mathrm{p}-\text { value })\end{array}$ & $\begin{array}{r}-0.4068^{* * *} \\
(-10.5515,2.2 e-16)\end{array}$ & $\begin{array}{r}\text { EngleLM(2) } \\
\text { (Probability) }\end{array}$ & $\begin{array}{r}0.6564 \\
(0.7202)\end{array}$ \\
\hline $\begin{array}{r}\text { Kurtosis } \\
(\mathrm{z}-\text { statistic, } \mathrm{p}-\text { value })\end{array}$ & $\begin{array}{r}8.0388^{* * *} \\
(29.7265,2.2 e-16) \\
\end{array}$ & $\begin{array}{r}\mu \\
(\mathrm{z}-\text { statistic }) \\
\end{array}$ & $\begin{array}{r}0.00026^{* *} \\
(2.4299) \\
\end{array}$ \\
\hline $\begin{array}{r}\text { Jarque }- \text { Bera } \\
(\mathrm{p}-\text { value })\end{array}$ & $\begin{array}{r}10869.99^{* * *} \\
(0.0000)\end{array}$ & $\begin{array}{r}\phi_{1} \\
(z-\text { statistic }) \\
\end{array}$ & $\begin{array}{r}0.1691^{* * *} \\
(15.2579)\end{array}$ \\
\hline$q 1 \%$ & -2.4432 & $\begin{array}{r}\phi_{2} \\
(z-\text { statistic }) \\
\end{array}$ & $\begin{array}{r}0.6769^{* * *} \\
(6.9853) \\
\end{array}$ \\
\hline$q 5 \%$ & -1.6230 & $\begin{array}{r}\theta_{1} \\
(\mathrm{z}-\text { statistic })\end{array}$ & $N A$ \\
\hline$q 95 \%$ & 1.5603 & $\begin{array}{r}\theta_{2} \\
(\mathrm{z}-\text { statistic }) \\
\end{array}$ & $\begin{array}{r}-0.7311^{* * *} \\
(-7.5155) \\
\end{array}$ \\
\hline$q 99 \%$ & 2.3612 & $\begin{array}{r}\theta_{3} \\
(z-\text { statistic }) \\
\end{array}$ & $\begin{array}{r}-0.1210^{* * *} \\
(-6.1262) \\
\end{array}$ \\
\hline$A R 1$ & -0.001 & $\begin{array}{r}\theta_{4} \\
(\mathrm{z}-\text { statistic }) \\
\end{array}$ & $\begin{array}{r}0.0491^{* * *} \\
(4.2774) \\
\end{array}$ \\
\hline$A R 2$ & 0.008 & $\begin{array}{r}\omega \\
(z-\text { statistic }) \\
\end{array}$ & $\begin{array}{r}1.96 e-06^{* * *} \\
(8.2497) \\
\end{array}$ \\
\hline$A R 3$ & -0.008 & $\begin{array}{r}\alpha \\
(\mathrm{z}-\text { statistic })\end{array}$ & $\begin{array}{r}0.0737^{* * *} \\
(4.7794) \\
\end{array}$ \\
\hline$A R 4$ & 0.013 & $\begin{array}{r}\beta \\
(\mathrm{z}-\text { statistic })\end{array}$ & $\begin{array}{r}0.8790^{* * *} \\
(90.7266)\end{array}$ \\
\hline$A R 5$ & -0.001 & $\begin{array}{r}\gamma \\
(z-\text { statistic })\end{array}$ & $\begin{array}{r}0.0771^{* * *} \\
(3.8216) \\
\end{array}$ \\
\hline$A R 6$ & -0.010 & Log - likelihood & 31987.06 \\
\hline $\begin{array}{r}\text { Q6 (residual) } \\
(\mathrm{p}-\text { value }) \\
\end{array}$ & $\begin{array}{r}3.9322^{* *} \\
(0.047) \\
\end{array}$ & Akaike criterion & -6.3864 \\
\hline $\begin{array}{r}\text { Q6 (squared residual) } \\
(\mathrm{p}-\text { value })\end{array}$ & $\begin{array}{l}2.0451 \\
(0.153)\end{array}$ & Number & 10014 \\
\hline
\end{tabular}




\section{Table 2: Threshold choice}

Table 2 presents the results of the threshold detection for the upper $(+Z)$ and lower $(-Z)$ tail of the CAC 40 stock index standardized returns. Mean Excess Function plot is the first visual inspection where selection is made around linear region. Stability plot is the second visual inspection method where selection is made around stability region. The given intervals denote the range of acceptable threshold. Visual guidance denotes a plausible threshold choice. The optimal selection method is an automated method consisting in minimizing asymptotic mean squared error.

\begin{tabular}{|r|r|r|}
\hline & $+\mathrm{Z}$ & $-\mathrm{Z}$ \\
\hline MEF plot & 1 & -1.5 \\
\hline Stability plot & {$[1 ; 2]$} & {$[-0.5 ;-1.5]$} \\
\hline QQ plot & 2.5 & -1.5 \\
\hline Optimal selection & 0.9547 & -1.3811 \\
\hline
\end{tabular}

\section{Table 3: Parameters estimates for the GPD model}

Table 3 gives parameter estimates of the General Pareto distribution fitted to the upper $(+Z)$ and lower tails $(-Z)$ of the CAC 40 stock index standardized returns. The generalized Pareto distribution is fitted to excesses over the selected threshold. The vector parameters are estimated by the maximum likelihood method. Nb. Exceedances corresponds to the number of observations in the tail. Percentile is the percentage of observations below the threshold. Neg. Lik is the negative logarithm of the likelihood evaluated at the maximum likelihood estimates.

\begin{tabular}{|r|r|r|}
\hline & $+\mathrm{Z}$ & $-\mathrm{Z}$ \\
\hline$\xi$ & -0.00055 & $0.14397^{* * *}$ \\
$(s . e)$ & $(0.0195)$ & $(0.0345)$ \\
\hline$\sigma$ & $0.5403^{* * *}$ & $0.5015^{* * *}$ \\
$(s . e)$ & $(0.0174)$ & $(0.0250)$ \\
\hline Threshold & 0.9547 & -1.3811 \\
\hline Nb.Exceedances & 1522 & 755 \\
\hline Percentile & 0.8480 & 0.9246 \\
\hline Neg.Lik. & 584.326 & 342.7594 \\
\hline $\begin{array}{r}\text { *** denotes parameter significantly different from zero } \\
\text { at the 99\% confidence level. }\end{array}$
\end{tabular}



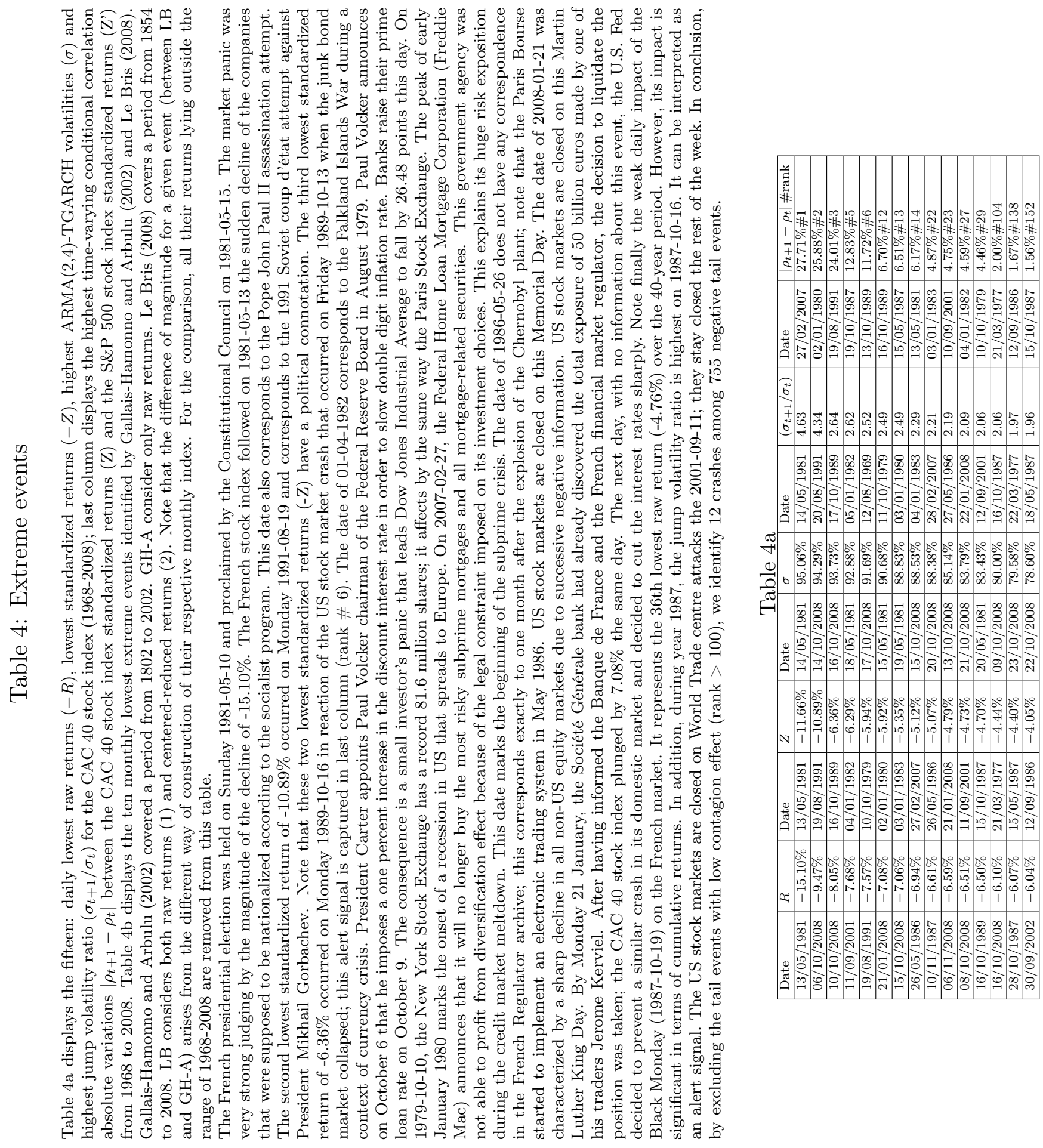
Table $4 \mathrm{~b}$

\begin{tabular}{|l|l|l|l|l|l|}
\hline Date & LB (1) & Date & LB $(2)$ & Date & GH - A \\
\hline May1981 & $-32.79 \%$ & May1981 & $-4.48 \%$ & November1987 & $-18.36 \%$ \\
\hline October1987 & $-25 \%$ & October1987 & $-3.49 \%$ & June1981 & $-14.37 \%$ \\
\hline May1986 & $-18.56 \%$ & September1998 & $-3.23 \%$ & October1987 & $-14.02 \%$ \\
\hline September1998 & $-17.66 \%$ & May1986 & $-2.89 \%$ & May1981 & $-12.96 \%$ \\
\hline July2002 & $-15.99 \%$ & November1973 & $-2.85 \%$ & August1990 & $-12.79 \%$ \\
\hline October2008 & $-14.99 \%$ & October2008 & $-2.79 \%$ & & \\
\hline September2002 & $-14.81 \%$ & & & & \\
\hline november1973 & $-14.31 \%$ & & & & \\
\hline August1990 & $-13.39 \%$ & & & & \\
\hline June1974 & $-12.82 \%$ & & & & \\
\hline
\end{tabular}

Table 5: Estimated risk measures

Table 5 gives for each probability level of $0.99,0.995,0.999,0.9995,0.9999$ the VaR and the associated Expected Shortfall estimates based on a (i) GPD model fitted to the CAC 40 stock index negative standardized returns $(-Z)$ and a (ii) normal distribution.

\begin{tabular}{|l|l|l|l|l|}
\hline Probability & VaR - GPD & ES - GPD & VaR - normal & ES - normal \\
\hline 0.9900 & -2.5570 & -3.3408 & -2.3263 & -2.6652 \\
\hline 0.9950 & -3.0461 & -3.9120 & -2.5758 & -2.8919 \\
\hline 0.9990 & -4.3886 & -5.4804 & -3.0902 & -3.3670 \\
\hline 0.9995 & -5.0699 & -6.2762 & -3.2905 & -3.5543 \\
\hline 0.9999 & -6.9402 & -8.4611 & -3.7190 & -3.9584 \\
\hline
\end{tabular}

Table 6: Estimated return levels

Table 6 displays the results of the return levels for 1,2, 5, 10, 20, 50 and 100 years. This table displays the result of the fit of the upper tail $(+Z)$ and lower tail $(-Z)$ of the CAC 40 stock index standardized returns. $2 \times 2$ columns represent upper and lower bound with $95 \%$ confidence interval.

\begin{tabular}{|l|l|l|l|l|l|l|}
\hline Period & $+\mathrm{Z}$ & Lower bound & Upper bound & $-\mathrm{Z}$ & Lower bound & Upper bound \\
\hline 1 & 2.9182 & 2.7994 & 3.0371 & -3.2143 & -3.0316 & -3.3970 \\
\hline 2 & 3.2920 & 3.1330 & 3.4510 & -3.7722 & -3.4975 & -4.0470 \\
\hline 5 & 3.7859 & 3.5582 & 4.0135 & -4.6006 & -4.1431 & -5.0581 \\
\hline 10 & 4.1593 & 3.8677 & 4.4509 & -5.3039 & -4.6522 & -5.9557 \\
\hline 20 & 4.5326 & 4.1669 & 4.8983 & -6.0811 & -5.1776 & -6.9846 \\
\hline 50 & 5.0259 & 4.5466 & 5.5052 & -7.2348 & -5.8935 & -8.5762 \\
\hline 100 & 5.3989 & 4.8219 & 5.9758 & -8.2145 & -6.4479 & -9.9811 \\
\hline
\end{tabular}

